Stavros C. Efremidis Prodromos Hytiroglou Osamu Matsui

\section{Enhancement patterns and signal-intensity characteristics of small hepatocellular carcinoma in cirrhosis: pathologic basis and diagnostic challenges}

Published online: 21 September 2007

(C) European Society of Radiology 2007

The online version of the original article can be found at http://dx.doi.org/10.1007/ s00330-007-0705-z.

\section{S. C. Efremidis $(\bowtie)$}

Department of Radiology, University of Ioannina Medical School,

P.O. Box 1186, 45110 Ioannina, Greece

e-mail: sefremid@cc.uoi.gr

\section{P. Hytiroglou}

Department of Pathology, Aristotle

University of Thessaloniki

Medical School,

54006 Thessaloniki, Greece

\section{O. Matsui}

Kanazawa University Graduate School of Medical Science,

13-1 Takara-machi,

Kanazawa, 920-8641, Japan
In the legend of Fig. 2, it is stated: "Reprinted from reference [30] with permission of the publisher, slightly modified".
The reference number is incorrect. The correct statement is: "Reprinted from reference [12] with permission of the publisher, slightly modified". 